\title{
Laser Doppler measurement of rectal mucosal blood flow
}

\author{
A V Emmanuel, M A Kamm
}

\begin{abstract}
Background-Gut mucosal blood flow measurement is used to study a variety of disorders and possibly extrinsic neural function.

Aims-To determine optimal measurement criteria and validate this technique as a measure of level of activity of extrinsic autonomic gut innervation.

Methods-In 26 healthy volunteers a laser Doppler mucosal probe was applied 10 cm from the anus. Response to inhaled salbutamol $200 \mu \mathrm{g}$ and ipratropium $40 \mu \mathrm{g}$, intravenous metoprolol $2.5 \mathrm{mg}$, and direct sacral nerve electrostimulation (in nine incontinent patients) was also studied.

Results-The coefficient of variation for subjects studied under identical conditions on two, three, and four days was $\mathbf{0 . 0 6}$, 0.05 , and 0.06 , respectively. Mean mucosal blood flow increased after a standard meal. Blood flow decreased for 15 minutes after smoking and returned to baseline at 30 minutes. Fasted measurements at 0900 , 1200,1600 , and 2200 were similar. There was a negative correlation between blood flow and body size but not age. Follicular phase mucosal flow was less and more reproducible than luteal. Mucosal blood flow was highest in men and lowest in postmenopausal women. Inhaled salbutamol did not change blood flow; ipratropium significantly reduced, and metoprolol and sacral nerve stimulation increased flow.

Conclusions-Measurement of gut mucosal blood flow by laser Doppler flowmetry is highly reproducible. Eating, smoking, body size, sex, ovulatory status, and menstrual phase influence blood flow. Changes in mucosal blood flow induced by autonomically active drugs and nerve stimulation confirm the role of the mucosal microcirculation as a measure of extrinsic nerve activity.

(Gut 1999;45:64-69)
\end{abstract}

Keywords: laser Doppler flowmetry; rectum; autonomic nervous system; blood flow

Physiology Unit, St Mark's Hospital, Northwick Park, Harrow, Middlesex HA1 3UJ, UK

A V Emmanuel

M A Kamm

Correspondence to: Dr Kamm.

Accepted for publication 13 January 1999 sic autonomic innervation. Existing measures of autonomic activation relate to the cardiovascular system, skin, and circulating hormones. ${ }^{1}$ However, their level of activity may bear no relation to level of gut activation, because of the special-
In many functional gastrointestinal disorders it is unknown whether the symptoms and physiological abnormalities relate to a process which is ised pathways from the brain which innervate the different organ systems. In view of the fact that gastrointestinal mucosal blood flow is thought to be regulated at least in part by the extrinsic nerve supply, ${ }^{23}$ we have postulated that assessment of mucosal blood flow may provide a sensitive quantitative measure of the level of activity of the nerves innervating the gut. Mucosal blood flow is also influenced by local neural and endocrine factors, but given a steady state situation the variation in blood flow may be accounted for by differences in extrinsic nerve activity.

Laser Doppler flowmetry (LDF) has found clinical application in a variety of vascular disorders such as skin grafting, ${ }^{4}$ Raynaud's phenomenon, ${ }^{5}$ and cerebral hypoperfusion. ${ }^{6}$ In the gut, use of this technique has been limited to the study of perfusion in inflammatory or vascular diseases and to study anastomotic blood flow. ${ }^{78}$ Erosive duodenitis, ${ }^{9}$ ulcerative colitis, ${ }^{10}$ and the ileal pouch ${ }^{11}$ have all been shown to be associated with reduced mucosal perfusion, although other studies in ulcerative colitis have shown increased flow. ${ }^{12} 13$ The possible application of this technique to study the neural regulation of the microcirculation, as opposed to the effects of inflammation or trauma, opens up a new means of studying functional disorders.

This study aimed to establish the reproducibility of this technique, to determine which physiological variables affect mucosal flow, and lastly to confirm that mucosal regulation is influenced by extrinsic autonomic nerve activity.

\section{Materials and methods}

PRINCIPLES AND TECHNIQUE OF LASER DOPPLER FLOWMETRY

A DRT4 laser Doppler flowmeter (Moor Instruments, Devon, UK) was used, which produces a low intensity beam almost exclusively of monochromatic coherent $780 \mathrm{~nm}$ light generated by a near infrared laser diode source and delivered by a fibreoptic probe. LDF measures the frequency shift in light reflected from a moving object. In tissue, red blood cells account for most of the moving structures, and the speed of their movement determines the frequency of light which is reflected. Reflected light is detected by a photocell and the signal processed to determine the frequency shift. As the volume under observation is relatively constant apart from slight changes with vasodilatation, the volume flow (or "flux") usually approximates to $\mathrm{ml}$ of blood per minute per $100 \mathrm{~g}$ tissue. The approximate area of

Abbreviations used in this paper: $\mathrm{CV}$, coefficient of variation; $\mathrm{LDF}$, laser Doppler flowmetry. 
measurement is $1 \mathrm{~mm}^{2}$ at up to $1 \mathrm{~mm}$ depth from the tip of the probe. The DRT4 uses a bandwidth of $14.9 \mathrm{kHz}$ and has an inbuilt microprocessor which calculates the flux over any desired time period. The probe (DP6A) also monitors the temperature of the surface under study. With routine application of the probe to the mucosa there is minimal change in flux. The outside diameter of the probe was $2.1 \mathrm{~mm}$ and was a two fibre probe (fibre diameter: $200 \mu \mathrm{m}$ core, $500 \mu \mathrm{m}$ with cladding; fibre separation $500 \mu \mathrm{m})$. Movement artefact is also eliminated by the built in software which averages recorded values over 0.1 second time intervals.

BLOOD FLOW MEASUREMENT PROTOCOL

Patients were examined in the left lateral position with no prior bowel preparation in a room with a constant ambient temperature of $22^{\circ} \mathrm{C}$. Examination with a rigid sigmoidoscope using minimal insufflation confirmed that the rectum was empty. The probe was then placed against the mucosa $10 \mathrm{~cm}$ above the lower limit of the anal margin under direct visualisation after air had been released. Stable readings were invariably obtained after 30 seconds. Studies in our laboratory over 30 minutes had revealed no change in flux measurement after stabilising at 30 seconds. A recording was taken for three minutes after a stable recording was obtained. Four recordings of blood flow were made at $90^{\circ}$ circumferentially, and the mean of these taken as the mucosal flux.

Rigid sigmoidoscopy could conceivably influence autonomic function, as a result of acute stress. However, this procedure was the same in every subject, and during all experiments, and should therefore not have served as a variable.

For those studies in which inhaled autonomically active drugs were used, skin blood flow was measured simultaneously with rectal mucosal blood flow. Skin blood flow was recorded using a probe placed on the skin of the S2 dermatome.

SUBJECTS

Twenty six healthy volunteers (seven men; mean age 37 years, range 18-61) were studied on two to four consecutive days. None had gastrointestinal, cardiovascular, or respiratory disease on history or examination. The only regular medications consumed were anticonvulsants taken by two subjects. In the six volunteers who smoked regularly all studies were performed at least six hours after the last cigarette as it is known that smoking reduces mesenteric arterial and mucosal blood flow. ${ }^{14}$

NUMBER OF MEASUREMENTS REQUIRED TO ACHIEVE REPRODUCIBILITY

The initial study was designed to determine the number of measurements required at a fixed site to obtain optimum reproducibility of the technique, that is, the minimum coefficient of variation $(\mathrm{CV}=$ standard deviation/mean $)$. The $\mathrm{CV}$ is an index of the amount of variation between readings taken under identical circumstances. Twelve healthy volunteers (six men, median age 32.4 years, range $25-51$; six women, median age 31.7 years, range 27-41) were studied.
Seven to 10 (mean 8.8) flow measurements were made every three to four minutes over a 30 minute period. Four readings were sufficient to produce a coefficient of variation less 0.10 and hence for the rest of the study four measurements were taken at each site.

DAY TO DAY REPRODUCIBILITY

All 26 healthy volunteers were studied on two to four consecutive days: six were studied on two days, 12 on three days, and eight on four days.

EFFECT OF FOOD INGESTION ON BLOOD FLOW AND REPRODUCIBILITY

Five men were studied five times on the same day before, and two, four, six, and eight hours after a meal. Blood flow returned to baseline after four hours, which then determined the shorter duration of subsequent studies on the effect of food.

To investigate the effect of food, 18 subjects (six men) were studied after a six hour fast and 30 and 60 minutes after a standard meal of 400 $\mathrm{ml}$ warmed cream of chicken soup (Heinz) on two consecutive days.

EFFECT OF SMOKING ON BLOOD FLOW AND REPRODUCIBILITY

Four men and two women, all of whom were established smokers, were studied at baseline and $5,15,30$, and 60 minutes after smoking a medium tar cigarette. All studies were performed after a minimum six hour fast.

EFFECT OF TIME OF DAY ON BLOOD FLOW

Seven women and seven men had measurements performed at 0900, 1200, 1600, and 2200 in order to identify any diurnal variation. The first two measurements were taken on a separate day to the latter two measurements. Subjects had been fasted for a minimum of four hours prior to these measurements. Other variables were also kept constant, such as phase of the menstrual cycle and abstinence from smoking.

EFFECT OF MENSTRUAL CYCLE ON BLOOD FLOW Fifteen women were studied between two and four times in both the follicular (mean 3.6) and luteal phases (mean 3.5) of the menstrual cycle. The follicular phase was defined as within 14 days of commencement of menstruation, and the luteal phase was defined as the following two weeks. Four other postmenopausal women were studied on three occasions. All studies were performed after a minimum six hour fast.

EFFECT OF SEX AND BODY SIZE ON MUCOSAL FLOW AND REPRODUCIBILITY

Comparison of baseline fasted mucosal blood flow values was made between men and women in either phase of the menstrual cycle. The association between body mass index and rectal mucosal blood flow was also investigated.

EFFECT OF INHALED SALBUTAMOL AND IPRATROPIUM ON RECTAL MUCOSAL BLOOD FLOW We also wished to determine whether extrinsic nerve activity could be altered using inhaled pharmacologically active autonomic drugs, and whether this could be reflected in mucosal 
blood flow changes. We hypothesised that if a rapid response was observed, this would be much more likely to relate to effects on extrinsic nerves, rather than on intrinsic gut nerves. Double blinded, placebo controlled, randomised studies of the effect of inhaled salbutamol and ipratropium were conducted. Twenty two healthy volunteers (seven men, mean age 33 years) were studied on four separate occasions. Two sets of two studies were performed, each set comparing active drug and placebo. Inhalers were not labelled and used a spacing device to ensure adequate lung exposure to the inhaled drug. One set of studies compared a metered $200 \mu \mathrm{g}$ dose of salbutamol with placebo, and another set of studies compared a metered $40 \mu \mathrm{g}$ dose of ipratropium with placebo. A 60 minute washout period was allowed between each administration of inhaled drug. Mucosal flux was measured 30 seconds after inhalation. Simultaneous measurement of blood flow in both the rectum and skin was undertaken to ascertain that a sufficient dose of inhaler had been consumed in order to alter at least dermal blood flow.

Salbutamol is a $\beta_{2}$ agonist. It was chosen because of the limited availability of inhaled $\beta$ agonists, although it was recognised that the gut has a predominantly $\beta_{1}$ innervation. However, the skin has a $\beta_{2}$ innervation, so it was possible to use an effect on skin blood flow as a marker of absorption. Ipratropium is a muscarinic antagonist, which might be expected to diminish the positive cholinergic drive to mucosal blood flow.

EFFECT OF INTRAVENOUS METOPROLOL ON MUCOSAL BLOOD FLOW

Eight healthy volunteers (seven men, mean age 33 years) underwent a double blind, placebo controlled, randomised study of the effect of $2.5 \mathrm{mg}$ intravenous metoprolol on mucosal blood flow. Measurements of mucosal blood flow, heart rate, and blood pressure were made at baseline, and $5,10,15,30,45,60$, and 120 minutes after administration of the $\beta_{1}$ adrenoceptor antagonist. The placebo and active drug administrations were performed two weeks apart, and all patients were fasted for a minimum of six hours.

EFFECT OF SACRAL NERVE STIMULATION ON MUCOSAL BLOOD FLOW

Nine female patients (mean age 46 years, range 36-55) with faecal incontinence and anatomically intact sphincters who were undergoing an experimental therapy of sacral nerve stimulation $^{15}$ underwent measurement of rectal mucosal blood flow. Readings were obtained as the stimulation current was increased in a stepwise fashion ( $1 \mathrm{~mA}$ increments) until discomfort threshold was reached. The stimulation was at $20 \mathrm{~Hz}$ and a pulse width of $200 \mu \mathrm{sec}$, using a monopolar electrode.

STATISTICAL METHODS

Data were normally distributed and are presented as mean (SEM). Variation of repeated measurements made in the same session at the same site were assessed using the coefficient of variation (CV). The two tailed paired $t$ test was used to analyse the effect of meals, the time of day, phase of the menstrual cycle, and autonomically active drugs. Correlations between variables were analysed by bivariate analysis. Regression was analysed by variance analysis. The Wilcoxon rank test was used to compare differences between the premenopausal and postmenopausal subjects, as the standard deviation in the former was greater than in the latter. All flux values are given as the mean (SEM). Probability values of less than 0.05 were regarded as significant.

\section{Results}

DETERMINATION OF OPTIMUM NUMBER OF MEASUREMENTS

Table 1 shows the relation between number of blood flow measurements and the CV. A CV of $10 \%$ or less is generally regarded as acceptable. ${ }^{78}$ Therefore no additional benefit was gained by performing more than four measurements at a site, and further studies consisted of determining the mean of four recordings per site.

DAY TO DAY REPRODUCIBILITY

The weighted mean $\mathrm{CV}$ between flux values measured on different days was 0.05 . The $\mathrm{CV}$ was 0.07 for subjects studied on two occasions, 0.05 for those studied on three occasions, and 0.06 for those studied on four occasions, confirming that this technique had good day to day reproducibility.

EFFECT OF MEALS ON MUCOSAL BLOOD FLOW The first study in five men was designed to determine the effect of a meal on mucosal flux. This showed that for at least two hours after a meal mucosal flux remained elevated with values similar to those immediately postprandially. Flux values were 208.2 (17.6) flux units (FU) at baseline, $259.0(21.6)$ at 30 minutes, 267.5 (27.9) at 60 minutes, and 258.4 (23.1) at two hours. All these postprandial values differed significantly from baseline $(p=0.03$, $p=0.03$, and $p=0.05$ respectively). The $C V$ was significantly smaller when fasted compared with after meals: 0.10 fasted, 0.19 at 30 minutes, 0.18 at 60 minutes, and 0.18 at two hours $(\mathrm{p}<0.05$ for postprandial values compared with fasted).

A larger study was then conducted with 18 subjects to determine the time required for mucosal flux to return to baseline after a meal. Mucosal flux values four, six, and eight hours after a meal were 196.2 (12.9), 187.4 (15.1), and 195.8 (16.5) respectively, none of which

Table 1 Relation between number of flux readings made at one site and the coefficient of variation $(C V)$ of the measurements

\begin{tabular}{lll}
\hline Number of readings & Mean $C V$ & Range $C V$ \\
\hline 2 & 0.144 & $0.073-0.317$ \\
3 & 0.132 & $0.072-0.208$ \\
4 & 0.082 & $0.050-0.126$ \\
5 & 0.076 & $0.067-0.125$ \\
6 & 0.072 & $0.058-0.110$ \\
7 & 0.065 & $0.052-0.102$ \\
8 & 0.068 & $0.052-0.116$ \\
\hline
\end{tabular}


Table 2 Variation of mean mucosal flux and coefficient of variation (CV) with sex, phase of the menstrual cycle, and menopause

\begin{tabular}{lllll}
\hline & $\begin{array}{l}\text { Female luteal } \\
(n=15)\end{array}$ & $\begin{array}{l}\text { Female follicular } \\
(n=15)\end{array}$ & $\begin{array}{l}\text { Postmenopause } \\
(n=4)\end{array}$ & $\begin{array}{l}\text { Male } \\
(n=7)\end{array}$ \\
\hline Mean flux (FU) & 204.1 & 183.9 & 155.4 & 210.2 \\
Mean CV (\%) & 0.162 & 0.101 & 0.0073 & 0.119 \\
\hline
\end{tabular}

significantly differed from each other, and none of which significantly differed from the baseline level of 200.4 $(\mathrm{p}=0.29, \mathrm{p}=0.18$, and $\mathrm{p}=0.28$ respectively).

EFFECT OF SMOKING ON MUCOSAL BLOOD FLOW It was shown that following a cigarette there was a temporary reduction of mucosal flux compared with baseline. Flux values compared with baseline $199.4(16.2)$ FU were 171.9 $(16.8)$ at five minutes $(\mathrm{p}<0.01), 175.4(17.8)$ at 15 minutes ( $\mathrm{p}<0.03), 205.7(22.0)$ at $30 \mathrm{~min}-$ utes $(\mathrm{p}=0.68)$, and $203.8(22.2)$ at 60 minutes $(\mathrm{p}=0.75)$ after the cigarette.

\section{EFFECT OF TIME OF DAY ON MUCOSAL BLOOD} FLOW

There were no differences in mucosal circulation identified with measurements taken on the same subjects at different times of the day. Values at $0900,1200,1600$, and 2200 were 197.5 (11.2), 198.8 (9.0), 196.4 (10.9), and 201.1 (11.7) FU respectively, none of which differed significantly from each other.

VARIABILITY OF MUCOSAL FLUX DURING THE MENSTRUAL CYCLE

Table 2 shows mucosal flux in different phases of the menstrual cycle and in postmenopausal

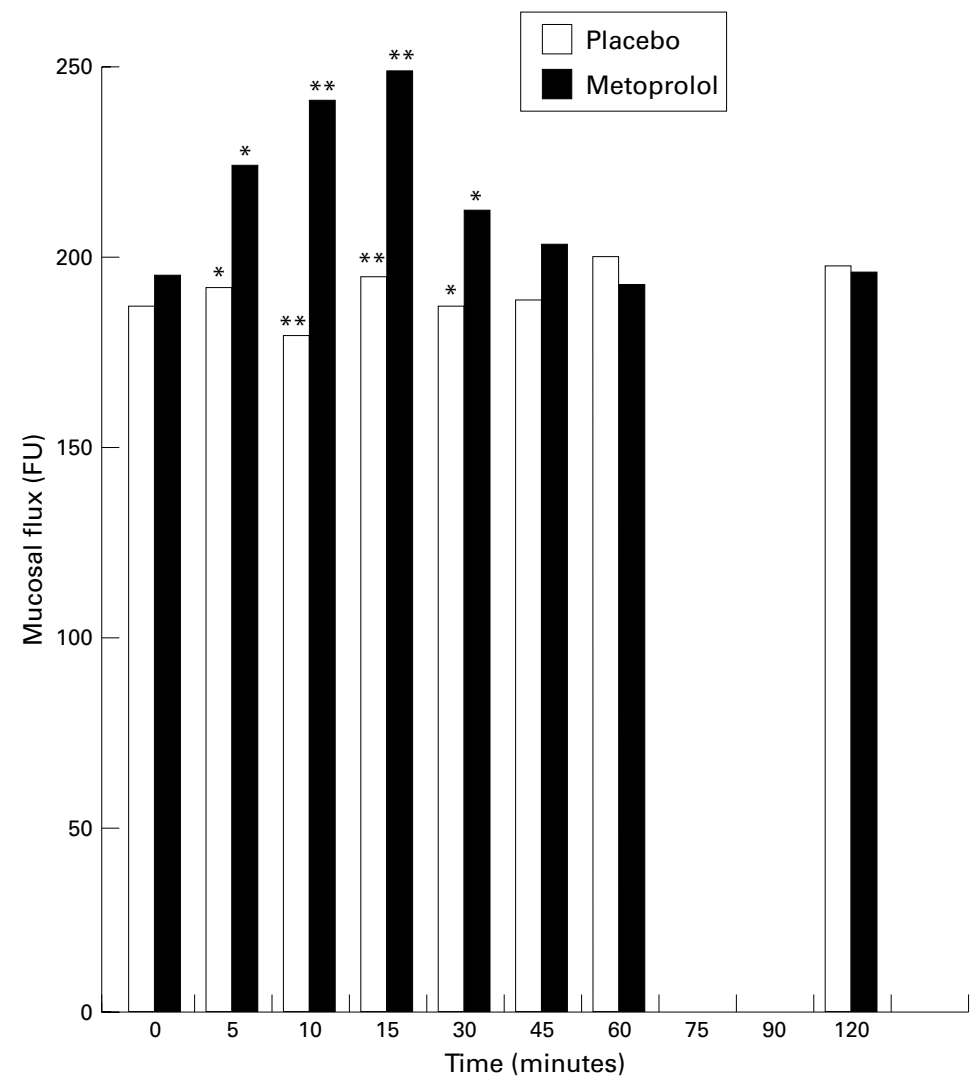

Figure 1 Effect of $2.5 \mathrm{mg}$ intravenous metoprolol and placebo on rectal mucosal blood flow in eight healthy volunteers. Bars represent mean data. ${ }^{\star} p<0.05,{ }^{\star \star} p<0.01$. women. Mucosal flux in the follicular phase was significantly lower than in the luteal phase, and follicular phase measurements were significantly more reproducible. Thirteen of the 15 subjects showed a difference between the two phases of the menstrual cycle.

In the four postmenopausal women the flux values were lower and the range of flux values was much tighter, resulting in a smaller $\mathrm{CV}$ in this group. In view of the small number studied this was not tested for statistical significance.

DIFFERENCES IN MUCOSAL FLUX BETWEEN MALES AND FEMALES

Rectal mucosal flux was significantly higher in men than women in the follicular phase of the menstrual cycle, but not in the luteal phase due to the wide range of values in the latter (table 2 ). The coefficient of variation of flux was similar in men to that in women in the follicular phase of the menstrual cycle.

\section{RELATION BETWEEN BODY SIZE AND MUCOSAL} FLUX

No correlation was identified between body mass index and rectal mucosal blood flow in the group of 26 healthy volunteers $(r=0.29$, $\mathrm{p}=0.10)$. Within sex comparisons also revealed no relation between body mass index and mucosal flux (men: $r=0.31, \mathrm{p}=0.09$; women: $r=0.21, \mathrm{p}=0.18)$.

\section{RELATION BETWEEN AGE AND MUCOSAL FLUX}

There was no correlation between age and rectal mucosal blood flow in the group of 26 healthy subjects $(r=-0.25, \mathrm{p}=0.19)$. Within sex comparisons also revealed no relation between age and flux (men: $r=-0.17, \mathrm{p}=0.24$; women: $r=-0.43, \mathrm{p}=0.09)$.

\section{EFFECT OF INHALED BRONCHODILATORS ON} MUCOSAL BLOOD FLOW

In the 22 healthy individuals there was a significant reduction in mucosal blood flow in response to inhaled ipratropium compared with placebo (mean reduction $15.7 \%$ with ipratropium versus $2.5 \%$ with placebo, $\mathrm{p}<0.01$ ).

Inhaled salbutamol did not significantly affect rectal mucosal blood flow in healthy individuals (mean increase $2.3 \%$ with salbutamol versus $0.2 \%$ with placebo, $\mathrm{p}=0.20$ ). However, skin blood flow was significantly reduced by inhalation of salbutamol compared with placebo (mean reduction $13.1 \%$ with salbutamol versus $0.8 \%$ with placebo, $\mathrm{p}<0.01$ ).

\section{EFFECT OF INTRAVENOUS METOPROLOL ON} MUCOSAL BLOOD FLOW

Intravenous metoprolol induced a reduction of heart rate (by a mean of $21 \%$ with metoprolol versus $2 \%$ with placebo, $\mathrm{p}<0.001$ ) and mean arterial pressure (by a mean of $12 \%$ with metoprolol versus $2 \%$ increase with placebo, $\mathrm{p}<0.003$ ). It simultaneously produced a significant increase in colonic mucosal blood flow, which peaked (increased flow by $30 \%$ compared with placebo) at 15 minutes after administration and persisted for 30 minutes (fig 1). 
Figure 2 Typical graph of effect seen of direct sacral nerve stimulation on rectal mucosal blood flow in a patient with faecal incontinence.

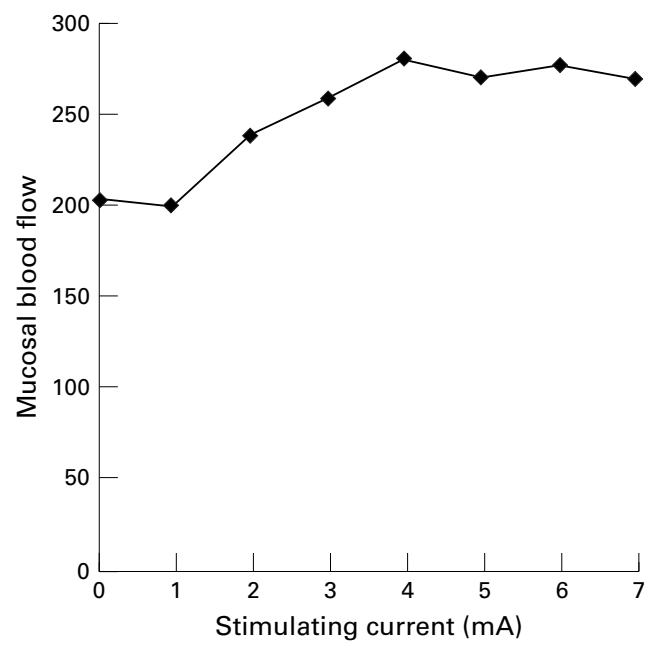

EFFECT OF SACRAL NERVE STIMULATION ON MUCOSAL BLOOD FLOW

The mean discomfort threshold for the patients was $5.4 \mathrm{~mA}(4.0-7.0 \mathrm{~mA})$ and in all patients, as stimulation current was increased, there was a corresponding increase in mucosal blood flow until a "plateau" level of mucosal vasodilatation was reached (fig 2). The mean stimulation current to achieve the plateau was $4.0 \mathrm{~mA}$ (3.0-5.0 mA).

\section{Discussion}

This study has shown that rectal mucosal blood flow can be reproducibly measured. Factors which affect this measurement have also been determined, allowing for optimal study conditions to be defined.

LDF offers a non-invasive means of studying circulation in a variety of microvascular beds. It has particular application to the gut mucosa, which receives the highest vascular perfusion of any organ, as measured by the rate of oxygen consumption. ${ }^{16}$ The technique has been used to study colonic blood flow as an index of organ viability after anastomosis ${ }^{71} 18$ and prolonged hypoperfusion. ${ }^{19}$ In patients with ulcerative colitis it has been used to study colonic mucosal blood flow but with widely discrepant results. ${ }^{10} 12$ It is therefore important to assess the optimal conditions for mucosal flux measurement. The probe we have used allows highly reproducible measurements to be made, and we have defined the circumstances required to obtain consistent results.

Four readings taken circumferentially at $90^{\circ}$ to each other at $10 \mathrm{~cm}$ from the anal verge provided results which differed only slightly from each other. The CV was comparable or better than that recorded with LDF in other microvascular beds. $^{82021}$

Previous animal and human studies have shown LDF to be at least as accurate a measure, or even a better measure of microcirculatory flow than other established techniques such as tonometry, ${ }^{22}$ reflectance spectrophotometry, ${ }^{22}{ }^{23}$ pulse oximetry, and ultrasound flowmetry. ${ }^{24}$ Key advantages of LDF over these other methodologies include the fact that it is less invasive and relatively free of movement artefact. When applied to a mucosal site a steady state trace was invariably obtained within 30 seconds. Values obtained were highly reproducible with only minimal variation from one day to another, suggesting that a single measurement is an accurate reflection of tissue perfusion. The test was safe and well tolerated by all subjects.

This study has established for the first time which variables may affect rectal mucosal blood flow in healthy subjects. One report describing the methodological aspects of the technique $^{7}$ was limited to the study of older patients with a variety of gastrointestinal and cardiovascular diseases who had undergone bowel preparation and opiate premedication.

Minimum variability of recorded flux was observed in fasted patients. Eating induced a significant rise and increased variability in mucosal blood flow, and so all subsequent studies were performed in the fasted state. A four hour fast was found to be adequate for flux values to return to baseline values. Our findings in relation to smoking complement those of Zhang and Leung ${ }^{14}$ who observed a dose related reduction of flux with cigarette smoke in anaesthetised rats.

Rectal microcirculatory flux was not shown to be subject to diurnal variation. This agrees with the results of animal studies using radioisotope and particle dilution techniques. ${ }^{2}{ }^{16}$ Diurnal variations in blood flow are therefore more likely to relate to meals than to intrinsic circadian rhythm.

In keeping with previous observations of cyclic changes in pelvic blood flow, ${ }^{25}$ we found variations in rectal mucosal blood flow during the menstrual cycle. Flow was increased and more variable during the luteal phase. Postmenopausal women had a significant reduction of blood flow compared with women in either phase of the menstrual cycle. In the absence of ovarian activity, as occurs in postmenopausal women, peripheral blood flow is relatively lower at rest than that found in premenopausal women. These observations highlight the importance of hormonal influences in modulating pelvic blood flow ${ }^{26}$ and the need to control for this variable when investigating rectal blood flow. The increased rectal microvascular flux seen in men compared with women may be related to the endocrine environment. The peripheral blood flow changes that we have observed in relation to the ovarian cycle are likely, at least in part, to be due to the secretion of oestrogen and progesterone. Both these hormones are strongly vasoactive but their effects are often difficult to interpret, varying with the site of action, duration of exposure, and species in animal studies. ${ }^{27}$ Age had no specific demonstrable effect on mucosal blood flow in this group of healthy volunteers who had no cardiovascular disease.

Rectal mucosal blood flow was shown to be increased by an intravenous $\beta$ adrenoceptor antagonist. Inhalation of a $\beta$ adrenoceptor agonist produced no alteration of mucosal blood flow, but did affect skin perfusion. This suggests that an adequate blood level was achieved to affect peripheral $\beta_{2}$ adrenoceptors. The most likely explanation for the absence of gut response is a low $\beta_{2}$ receptor density in gut 
blood vessels. A previous study in the human sigmoid colon ${ }^{28}$ showed that metoprolol increased motor activity. Coupled with our findings this would suggest the presence of a tonically active $\beta_{1}$ adrenoceptor inhibitory pathway which controls colonic mucosal blood flow and motility. Although $\beta_{2}$ adrenoceptors have been identified in colonic tissue of rats, ${ }^{29}{ }^{30}$ it is unknown whether human colonocytes have a similar receptor population. Our data have failed to show a role for them in controlling mucosal blood flow.

We have produced evidence from both pharmacological and nerve stimulation studies that extrinsic nerves play a major role in controlling mucosal blood flow. However, we do not believe that extrinsic nerves are the only factor influencing mucosal blood flow. Inflammation, and possibly other factors, may cause a notable change in the local neural regulation of blood flow. However, given a steady state situation in which intrinsic factors are likely to be similar in different subjects, mucosal blood flow seems to be a good reflection of the level of activity of extrinsic nerves. We cannot exclude the possibility that some of the altered mucosal blood flow that one might observe in patients with a motility disorder is directly related to changes in the activity of intrinsic nerves. We have not addressed this aspect of control in these studies.

We have shown that there is a reduction of colonic mucosal blood flow in response to inhalation of ipratropium, a muscarinic receptor antagonist. It is known that in mammalian species ${ }^{31}$ muscarinic receptors are involved in colonic secretion and our findings argue in favour of a tonically active cholinergic muscarinic mechanism which increases mucosal blood flow. We cannot exclude the fact that some of these changes were produced by a direct effect of the drug on intrinsic gut neurones, although the rapid response makes this unlikely.

The vasodilator response of the colonic mucosa to direct sacral nerve stimulation suggests that there is a cholinergic mediated vasodilatory input to the mucosa which is effective via sacral spinal paraympathetic efferents. The response also confirms that mucosal blood flow alterations are brought about by nerve activation, hence providing strong support for the validation of rectal mucosal flux as an index of gut specific autonomic tone.

In conclusion, measurement of laser Doppler rectal mucosal blood flow is a reproducible technique. Sex, ovulatory status, menstrual phase, absence of smoking, and eating should be controlled for. The bowel need not be prepared providing that the mucosa being studied has been visualised. There is also evidence that mucosal blood flow measurements can be used as a tool to investigate the activity of intra-abdominal autonomic tone.

We are grateful to Dr C Dore for statistical advice, and to Dr A Roy for practical and technical help in performing this work.

1 Camilleri M, Ford MJ. Functional gastrointestinal disease and the autonomic nervous system: a way ahead? Gastroenterology 1994;106:1114-18.
2 Jodal M, Lundgren $\mathrm{O}$. Neurohormonal control of gastrointestinal blood flow. In: Schultz SG, Wood JD, Rauner BB, eds. Handbook of physiology. Section 6. The gastrointestinal system. Motility and circulation. Bethesda: American Physioogical Society, 1989:1667-711.

3 Burnstock G. Integration of factors controlling vascular tone-an overview. Anaesthesiology 1993;79:1368-80.

4 Schabauer AM, Rooke TW. Cutaneous laser Doppler flowmetry: applications and findings. Mayo Clin Proc 1994; 69:564-74.

5 Farrington NK, Sutej PG. Cold extremities: investigation and management of Raynaud's phenomenon. I Southern Orthopaedic Assoc 1996;5:37-45.

6 Bolognese P, Miller JI, Heger IM, et al. Laser Doppler flowmetry in neurosurgery. $\mathcal{F}$ Neurosurg Anesthesiol 1993;5:151-8.

7 Krohg-Sorensen $\mathrm{K}$, Line PD, Haaland $\mathrm{T}$, et al. Intraoperative prediction of ischaemic injury of the bowel: a comparison of laser Doppler flowmetry and tissue oximetry to histological analysis. Eur F Vasc Surg 1992;6:518-24.

8 Krohg-Sorensen K, Lunde OC. Perfusion of the human distal colon and rectum evaluated with endoscopic laser Doppler flowmetry. Methodologic aspects. Scand f Gastroenterol 1993;28:104-8

9 Guslandi M, Sorghi M, Foppo A, et al. Mucosal blood flow in erosive duodenitis. F Clin Gastroenterol 1993;17:201-3.

10 Guslandi M, Polli D, Sorghi M, et al. Rectal blood flow in ulcerative colitis. Am f Gastroenterol 1995;90:579-80.

11 Armstrong DN, Sillin LF, Chung R. Reduction in tissue blood flow in J-shaped pelvic ileal reservoirs. Dis Colon Rectum 1995;38:526-9.

12 Srivastava ED, Russell MAH, Feyerbrand C, et al. Effect of ulcerative colitis and smoking on rectal blood flow. Gut 1990;31:1021-4.

13 Cianci M, Gizzi G, Villani V, et al. Mucosal blood flow changes in ulcerative colitis measured by endoscopic laser Doppler flowmetry. Tech Coloproct 1996;2:80-3.

14 Zhang XY, Leung FW. Cigarette smoke aggravates acidinduced duodenal mucosal injury in the rat. Role of mesenteric vasoconstriction. Scand F Gastroenterol 1994;29: 214-18.

15 Vaizey CJ, Kamm MA, Turner IC, et al. Effects of short term sacral nerve stimulation on anal and rectal function in patients with anal incontinence. Gut 1999;44:407-12.

16 Granger DN, Kvietys PR, Korthuis RJ, et al. Microcirculation of the intestinal mucosa. In: Schultz SG, Wood JD, Rauner BB, eds. Handbook of physiology. Section 6. The gastrointestinal system. Motility and circulation. Bethesda: American Physiological Society, 1989:1405-74.

17 Senagore A, Milsom JW, Walshaw RK, et al. Does a proximal colostomy affect colorectal anastomotic healing? Dis Colon Rectum 1992;35:182-8.

18 Kashiwagi H, Konishi F, Furuta K, et al. Tissue blood flow of the sigmoid colon for safe anastomosis following ligation of the sigmoid colon for safe anastomosis following ligation of the infer 11 .

19 Diebel LN, Robinson SL, Wilson RF, et al. Splanchnic mucosal perfusion effects of hypertonic versus isotonic resuscitation of haemorrhagic shock. Am Surg 1993;59: 495-9.

20 Krohg-Sorensen K, Line PD, Kvernbo K. The significance of probe design in evaluation of colonic perfusion in laser Doppler flowmetry. Scand f Gastroenterol 1993;28:381-6.

21 Mevio E, Bernardi L. Phasic changes in human nasal and skin blood flow: relationship with autonomic tone. Ann Otol Rhinol Laryngol 1994;103:789-95.

22 Larson MV, Ahlquist DA, Karlstrom L, et al. Intraluminal measurement of enteric mucosal perfusion: relationship to superior mesenteric artery flow during basal and postprandial states in the dog. Surgery 1994;115:118-26.

23 Leung FW, Wong DN, Lau J, et al. Endoscopic assessment of blood flow in duodenal ulcers. Gastrointest Endosc 1994; 40:334-41.

24 Gardner GP, La Morte WW, Obi-Tabot ET, et al. Transanal intracolonic pulse oximetry as a means of monitoring the adequacy of colonic perfusion. F Surg Res 1994;57:537-40.

25 Hassan AAK, Tooke JE. Postural vasoconstriction in women during the menstrual cycle. Clin Sci 1990;78:39-47.

26 Marshall JS. Effects of ovarian steroids on adrenergic nerves of the uterus and oviduct. Am F Physiol 1981;240:C165-74.

27 van Buren GA, Yang DS, Clark KE. Estrogen-induced uterine vasodilatation is antagonised by L-nitroarginine methyl ester, an inhibitor of nitric oxide synthesis. Am $\mathcal{F}$ Obstet Gynecol 1992;167:828-33.

28 Abrahamsson H, Lyrenas E, Dotevall G. Effects of beta-adrenoceptor blocking drugs on human sigmoid colonic motility. Dig Dis Sci 1983;28:590-4.

$29 \mathrm{Ek} \mathrm{BA}$, Bjellin LAC, Lundgren BT. $\beta$-adrenergic control of motility in the rat colon I. Evidence for functional separation of the $\beta_{1}$ and $\beta_{2}$ adrenoceptor mediated

30 Ek BA, Nahorski SR. $\beta$-adrenergic control of motility in the rat colon II. Proportions of $\beta_{1}$ and $\beta_{2}$-adrenoceptors identified with ${ }^{125} \mathrm{I}-(-)$ pindolol binding. Gastroenterology 1986;90: 408-13.

31 Furness JB, Costa M. Identification of transmitters of functionally defined enteric neurones. In: Schultz SG, Wood JD, Rauner BB, eds. Handbook of physiology. Section 6. The gastrointestinal system. Motility and circulation. Bethesda: American Physiological Society, 1989:387-402. 